\title{
MÁs ALlÁ de la HiBRIDAD: LOS MEDIOS TELEVISIVOS Y LA PRODUCCIÓN DE IDENTIdades Indígenas en OAXaCA, MÉxico
}

\author{
Erica Cusi Wortham*
}

\section{TV Tamix sale al aire}

$\mathrm{E}$ 128 de noviembre de 1992, algo fuera de lo normal sucedió en el municipio Mixe de Tamazulapam del Espíritu Santo, Oaxaca. El mercado estaba cerrando, los comerciantes del valle empacaban para irse a casa y los otros habitantes hacían sus quehaceres cotidianos: las mujeres desplumaban gallinas, los niños disfrutaban paletas y dulces comprados en el mercado y los hombres disfrutaban de un baño. Los televisores emitían los noticieros, deportes o telenovelas favoritas, cuando la señal fue interrumpida y dos rostros familiares aparecieron en la pantalla. Armados con micrófonos y audífonos, dos profesores de la escuela primaria de Tamazulapam saludaron a la comunidad en castellano y ayuuk, a la vez que anunciaron una nueva estación televisiva: "¡Canal 12, TV Tamix de Tamazulapam!” Reloj en mano, uno de ellos repitió el día y la hora exacta para no dejar ninguna duda en las mentes de los televidentes de que se estaba trasmitiendo en vivo. Al principio nadie creía que la señal venía en realidad de Tamazulapam misma y se preguntaban cómo estos locos habían podido introducirse en un estudio televisivo en la ciudad de

${ }^{*}$ Erica Cusi Wortham, Investigadora huésped, Departamento de Antropología, Universidad de California, San Diego.
Oaxaca o en el Distrito Federal. Sin embargo, un niño reconoció el escenario - el patio de su escuela donde una antena había sido abandonada por años-y corrió por la calle para descubrir el equipo televisivo en acción: “¡Miren, miren! ¡Están en la secundaria!”.

Por primera vez en aproximadamente quince años, cuando los residentes de Tamazulapam empezaron a comprar televisores, los programas se relacionaban de manera directa a su identidad como gente indígena.

Los medios indígenas, entendidos como conocimiento tradicional plasmado en la tecnología moderna, de alguna manera ejemplifican una forma cultural híbrida. Como señala Homi Bhaba (1994), el concepto de la "hibridad" en su aplicación a las sociedades y los discuros poscoloniales nos permite entender la ambivalencia de la autoridad colonial y su constante subversión por parte de los colonizados como procesos tanto históricos como sociales. Néstor García Canclini (1989) refiere la "hibridez" para analizar la vitalidad del mestizaje en la cultura popular. Resulta útil esta noción para profundizar en los frecuentes estrechos entendimientos en torno a las identidades indígenas contemporáneas. Investigadores como Faye Ginsburg (1993) y Stuart Hall (1996) hacen percatarnos del cambio cultural y la formación de la identidad como prácticas autoconscientes, a diferencia de etnógrafos 
anteriores quienes estaban preocupados por el "cambio cultural" impuesto en las comunidades desde afuera (Redfield, 1968; Kuroda, 1984). No obstante, con el concepto de hibridez corremos el riesgo de caer en falsos dualismos: tradicional/moderno, urbano/rural o alternativo/masivo. Dualismos que no reflejan adecuadamente las facetas, los agentes y los múltiples intereses relacionados con la producción y circulación de identidades indígenas en video. Es necesario plantearse la cuestión en términos más abarcadores que el de hibridez, para reconocer que las identidades indígenas se producen pluralmente a través de relaciones sociales que involucran, en este caso, a agencias de gobierno, maestros de video independientes, etnógrafos, activistas, patrocinadores, programadores y creadores de video indígena, lo que muestra que las identidades indígenas son algo complejo, contestado y no reductible.

El presente estudio centra su reflexión en los esfuerzos claros, visibles y autoconscientes para lograr un cambio social a través del desarrollo del llamado "video indígena," fenómeno multifacético que representa tanto un proceso como una forma social dentro de la cual están profundamente entrelazados el patrocinio del estado y la autonomía indígena. ${ }^{1}$ Apreciar la pluralidad nos permite reconocer nuestra propia complicidad en la movilización política de categorías como cultura e identidad. Mi propósito no es reconocer el trabajo de los antropólogos o negar la conexión real de la identidad a las vidas y patrones sociales y culturales - ni a los lugares e historias específicas - sino reconocer tres asuntos relacionados entre sí: 1) que como estudiosos de la cultura, compartimos el campo de producción de conocimientos con aquellos a quienes representamos; 2) que dentro de la identidad cultural hay un complejo de intereses actuando en su consolidación y representación; 3) que la identidad cultural —y su representación visual- es una herramienta construida y fundamentalmente política que se utiliza en luchas de cambio social. Estos aspectos se relacionan en el presente estudio con una discusión sobre cómo el video es introducido a comunicólogos indígenas al interior de las dinámicas sociales de una comunidad mixe.

El "video indígena" como tal llega a Tamazulapam del Espíritu Santo — a partir de aquí lo abreviaré como Tama - en 1992 por medio de un programa del Instituto Nacional Indigenista - INI - que presenta al video como una herramienta para reforzar la identidad cultural. $^{2}$ En la siguiente sección — titulada Enseñando video indígena - hablaré de cómo dicho video indígena se desarrolló de manera particular por los instructores del programa quienes buscaban fomentar una propuesta visual "auténtica" indígena, cuando en realidad estaban desarrollando activismo cultural. La manera de introducir el video - como un "espejo electrónico" - crea ciertas expectativas que subvierten el potencial del video indígena en la comunidad. En la segunda sección: Radio y Video Tamix, resumo brevemente los diez años de historia de un grupo de comunicadores indígenas, desde sus inicios en el proyecto estatal "Casa del Pueblo", su consolidación como estación de televisión local, hasta una crisis que deja al grupo sin una posición clara frente a su propia comunidad. En relación con la historia de la Radio y Video Tamix analizo algunas de las estrategias de implantación - cómo miembros del grupo tratan de insertar el video indígena dentro de la comunidad por medio de la evocación de modismos de la vida colectiva-, así como ciertas tensiones y contradicciones surgidas en la producción del video indígena que muestran la complejidad identitaria en el proceso de producción de sus programas. 


\section{Enseñanza del video indígena: en busca de alteridad estética y al encuentro de solidaridad política}

Fundado enteramente por el presidente Carlos Salinas de Gortari y su programa de "Solidaridad", el programa de video del INI capacitó aproximadamente a 85 indígenas que representaban a 37 organizaciones distintas de todo México por medio de una serie de talleres de video nacionales que se organizaron anualmente de 1990 hasta 1994 como parte fundamental del entonces nuevo programa "Transferencia de Medios Audiovisuales a Comunidades y Organizaciones Indígenas" — TMA(Cremoux, 1997). ${ }^{3}$ El título del programa indica la amplia iniciativa con que se inició el proyecto por el entonces director general del INI, el antropólogo Arturo Warman, de entregar o "transferir" funciones y recursos institucionales a manos indígenas. Los talleres nacionales de capacitación duraron de seis a ocho semanas y cubrieron lo básico de la preproducción — cómo concebir y organizar un video-, producción - técnica básica de usos de la cámara, encuadramiento y movimiento-y edición — cómo poner imágenes o secuencias juntas para contar una historia- Al final de cada taller, el INI daba a cada organización participante un paquete de producción de video completo, uno de los pocos ejemplos de transferencia "sólida" durante el periodo de Warman. Cientos de indígenas han sido entrenados desde la fase inicial de los talleres nacionales por medio de una serie de Centros de Video Indígena establecidos en varios estados de la república como segunda fase del programa de TMA, aunque los fondos para el programa han disminuido poco a poco desde 1994. Por medio del programa, miles de horas de videocintas han sido grabadas en y acerca de comunidades indígenas de México y se han editado cientos de programas. Éstos refieren temas tan diversos como la espiritualidad indígena o el SIDA, y circulan dentro y fuera del ambiente indígena. Mientras algunos programas son videoclips musicales y otros son ficciones cortas, los documentales realistas constituyen el género dominante del "video indígena." Estos videos se proyectan en gran variedad de ambientes - que a su vez representan la extensión de relaciones sociales en las cuales se inserta el video indígena-lo cual incluye comunidades indígenas — en ambientes familiares o domésticos y otros espacios colectivos como salas de cine improvisadas-, giras rurales y urbanas organizadas por el INI y por organizaciones no gubernamentales, festivales de cine y video internacionales, museos etnográficos y de arte y, de manera limitada, en televisión y cablevisión en Francia, México y Estados Unidos.

El programa de video del INI fue concebido en la Ciudad de México en las oficinas del Archivo Etnográfico Audiovisual que estaban en ese momento bajo la dirección del etnógrafo mexicano y también cineasta, Alfonso Muñoz. ${ }^{4}$ No obstante, el programa realmente fue desarrollado por tres profesionales de los medios de comunicación - personas urbanas y no indígenas quienes tenían un escepticismo saludable respecto de los proyectos del gobierno- durante los talleres mismos. La metodología de enseñanza a los maestros capacitadores se desarrolló sobre la marcha durante el trabajo y de una manera autorreflexiva e intuitiva. Su acercamiento incluía aspectos técnicos de producción y edición, así como el fomento de una perspectiva crítica hacia los medios en general. Los aspectos técnicos incluían algo de traducción y esfuerzos encaminados a que los alumnos le perdieran el miedo a la tecnología. Sin embargo, los maestros percibieron entre los participantes de los talleres el sentimiento de que la producción del video estaba simplemente más allá de su alcance. Además, no ayudaba el hecho de que toda la información sobre los equipos estuviera en inglés. Unos cuantos términos técnicos fueron traducidos al castellano como "balance de blanco" para "white balance" mientras que otros claramente no 
necesitaban traducción, como "focus," o eran usados en inglés como "zoom" y "play." En especial, el término "videasta" presentaba a los maestros dilemas de imposición foránea, y buscaron títulos más "orgánicos" como "creador de imágenes". El punto central era la percepción de que el programa de video estaba potencialmente creando artistas individuales o, como dijo el maestro responsable de enseñar producción, Carlos Cruz, "seres desvinculados", moldeados en sí mismos a pesar de la misión del programa de reforzar la solidaridad de la comunidad (Cruz, 2000). ${ }^{5}$

Detrás de lo que Cruz llamó su metodología de enseñanza "maravillosamente intuitiva" (Cruz, 2000) estaba un compromiso para facilitar la creación de un "idioma visual indígena" o al menos el de proveer las condiciones para que éste emergiera. De forma pragmática, este compromiso se tradujo en un intento de abstenerse de imponer convenciones estilísticas occidentales para permitir la emergencia de las visiones o el idioma visual de los capacitados. Los instructores constantemente se cuestionaban a sí mismos si ellos estaban, en efecto, reproduciendo una manera peculiar de ver al mundo, pero fueron forzados a reconocer que el cuestionamiento constante confundía a quienes se capacitaban, e impedía abordar los cuestionamientos estéticos. Como me relató Cruz: "nos dimos cuenta de que estábamos generando una confusión profunda, porque cuando los estudiantes escuchaban a los profesores decir 'así funciona pero no lo hagan así'... éstos respondían '¿Lo hacemos o no?' ‘qué diablos me está enseñando?"' (Cruz, 2000). Para el segundo taller, los maestros decidieron seguir un plan de enseñanza más convencional, es decir más parecido a la manera en que ellos mismos habían sido capacitados, con la esperanza de alentar posteriormente, con el análisis y la crítica del trabajo, el inicio de una "propuesta visual indígena".
A pesar de estos deseos, muchos de los capacitados en los talleres produjeron formatos estereotipados de televisión, hubo incluso entrevistadores que ponían atrevidamente el micrófono en la cara del entrevistado y narraciones "en off" mal hechas, y que reproducían lo que recibían de la televisión y radio comercial dominante. Quiero referirme un poco a esta "confusión profunda", porque es aquí donde surgen algunas contradicciones que después entran en juego en Tama. También, se puede entender la frustración de los maestros en relación con la dificultad de fomentar una propuesta indígena emergente con base en su inclinación por el género documental y, en particular, en su uso del término "espejo electrónico".

Al igual que la literatura de testimonio, el documental está estrechamente asociado con el imperativo de dar información histórica revelando realidades ignoradas de la vida de los indígenas, así como de otros grupos sistemáticamente oprimidos (Kearney y Varese, 1995). La preferencia por el documental surge de manera natural ya que los tres maestros tendían por su propio desarrollo profesional a este género. Esta preferencia, junto al hecho de que el programa de TMA nació dentro del Archivo Etnográfico Audiovisual del INI — brazo de producción de documentales etnográficosprefiguró al video indígena dentro del documental. Por otro lado, varios asuntos pragmáticos que tenían que ver con el hecho de grabar en comunidad con pocos recursos, y la necesidad de muchas organizaciones de tener un documento íntegro de sus actividades, llevaron a los maestros a preferir el documental sobre la ficción o, por ejemplo, el ensayo personal. Por estas razones, el documental fue enseñado "naturalmente" como el género de video indígena y continúa como el formato dominante en la mayoría de los medios de producción indígena en México actual —aunque está emergiendo una tendencia hacia el género de ficción.

La preferencia hacia tal género en sí se entiende y no es problemático, pero la combinación del 
documental con la enseñaza de video como un "espejo electrónico" produce ciertas contradicciones interesantes y problemáticas. El "espejo electrónico" consiste en una técnica de video que representa o reproduce la realidad al igual que un espejo en la mano o sobre un muro, de manera inmediata y transparente. El modismo fue una de las estrategias empleadas por los maestros para popularizar al video como algo común e inocuo y, sobre todo, fiel a la realidad. Porque, como explica un videasta mixteco en un breve relato escrito para un folleto de una muestra de video indígena que organizó el INI en 1994, "la TV no es la realidad" (Julián Caballero, 1994) pero, según la lógica del argumento, el video indígena sí lo es. La realidad que refleja es opuesta al mundo de mentiras representadas en los medios de comunicación masiva comercial, un mundo donde la gente indígena no se ve reflejada. El "espejo electrónico" —un aparato supuestamente neutral y transparente- se convierte en una herramienta de lucha bajo la enseñanza de los maestros del programa de TMA, y esta conversión de lo neutral a la lucha no se da sin problemas y contradicciones con otros objetivos del proyecto. El "video indígena" gira sobre la supuesta relación directa y sin mediación del mundo no fílmico, y tal relación no sólo debilita los esfuerzos de los maestros por desarrollar un acercamiento crítico hacia los medios en general, sino también limita su potencial de alentar una "propuesta indígena", tal vez un reto sobrado del experimento que Sol Worth y John Adair trataron de realizar entre los navajo a principios de la década de 1970 (1997). Al final, en la propuesta indígena que sostiene al video indígena - construida mutuamente por los realizadores indígenas y por los maestros activistas - no se trata de un lenguaje visual sino de una posición o postura política que se sustenta en la idea de que al mostrar la cultura en video, se refuerza la identidad cultural y por lo tanto se le puede defender mejor. El video indígena afirma la particularidad cultural a pesar de los procesos de homogeneización cultural promovidos por el proyecto nacional de mestizaje y forma parte de las luchas —organizadas y personales — de autonomía indígena.

La metodología de enseñanza "intuitiva" que se dio al inicio de los talleres nacionales, fue estandarizada en un manual de enseñanza en 1996, escrito de manera colaborativa por varios miembros del equipo del primer Centro de Video Indígena del INI, establecido en la ciudad de Oaxaca en 1994. En éste, se muestra claramente la labor del video indígena.

\footnotetext{
Si las culturas originales del continente americano son diferentes de las de origen europeo y mestizo, entonces la manera de expresarse a sí mismas con imágenes y sonidos no tienen que ser las mismas. La labor que tienen los creadores de video indígena es determinar cómo esta forma de comunicación puede servir para reforzar a sus propios pueblos, constru-yendo sobre sus propios modos de comunicación auditiva y visual como el lenguaje, historias tradicionales, música, símbolos, paisajes y figuras que aparecen en los textiles y en el arte. Las reglas y definiciones existen para ser desafiadas, cuestionadas y finalmente rotas si es necesario. Lo que está escrito aquí puede ser considerado como un punto de partida para que un día los creadores de video indígena puedan escribir sus propios manuales que propongan elementos y conceptos que resultarán en un verdadero video indígena. (CVI, 1996).
}

Un "verdadero" video indígena sigue siendo tan elusivo hoy como lo era a principios de la década de 1990, a pesar de los deseos o pretensiones de los instructores y de algunos creadores de video indígena que pretendían lo contrario. Lo que distingue al video indígena de otros géneros no son los marcadores formales y estéticos, ni los individuos involucrados en su producción —que incluye muchas veces a mestizos como editores y consejeros creativos-, sino una plataforma cultural y política compartida y comprometida. Cuando pregunté al videasta zapoteco Juan 
José García —el segundo director del Centro de Video Indígena en Oaxaca - en el 2000, diez años después del comienzo del proyecto del INI, sobre qué es el video indígena, éste me respondió: "el video indígena no existe” (García, 2000). Me explicó: "Tal vez existe lo que se podría llamar el "video zapoteco" o el "video Juan José," pero el video indígena es más una postura que un género audiovisual claramente diferenciado" (García, 2000). Como tal, esta postura refleja procesos de reclamo, incursiona en un espacio televisual del cual la gente indígena había sido previamente excluida y se construye con diferentes demandas del movimiento para la autonomía indígena.

La combinación de la enseñanza del documental como una forma comunicativa de compromiso social junto a la idea de la tecnología como algo transparente formó un género específico —el video indígena- que muestra ciertas debilidades frente a asuntos comunitarios en Tama, como veremos más a delante. Dichas carencias tienen que ver con una creencia sobre la capacidad del medio de "mostrar cultura", de hacer el trabajo del activista social sin realizar lo necesario para encajar el proyecto dentro de la dinámica social y estructuras de poder de una comunidad indígena. En fin, el poder del documental de comunicar y convencer se vio comprometido al suscribirse al modismo del espejo electrónico, en vez de mostrar que el videasta indígena - y por extensión el video que produce- ocupa una posición particular que le da su poder. ${ }^{6}$ Esta contradicción tal vez está en la base de la "profunda confusión" que identificó el maestro Cruz. Pasaremos enseguida a la discusión del proyecto de Radio y Video Tamix.

\section{Radio y Video Tamix: Ubicación de una organización de medios en la comunidad}

Llegué a Tama al iniciar mi investigación de campo en la noche del primer y principal tequio o labor comunal que se llevaba a cabo en los campos recientemente chapeados al centro del conflicto agrario con un pueblo vecino, Santa María Tlahuitoltepec - Tlahui en corto-. Dado el "estado de guerra" entre los dos pueblos, dudaba si había sido la mejor decisión llegar a Tama en un autobús administrado por el pueblo de Tlahui. Le pedí a un señor que viajaba a mi lado, que me avisara cuando llegáramos a Tama. Era de noche, pero con su ayuda pude bajarme en la curva correcta. Cuando me vieron, un topil —el sirviente civil en el rango más bajo del sistema de cargos comunales - quien convocaba a los comuneros en su idioma aymuk al tequio que tendría lugar, hizo una pausa y pasó el micrófono a la telefonista para que le llamara por éste medio al maestro Clemente Nuñez, un miembro fundador de Radio y Video Tamix, para que fuera a su casa a recibirme. Conocía Clemente por primera vez en 1993 en una conferencia de antropología en la Ciudad de México y participé junto con él en numerosas presentaciones de video indígena en Oaxaca y también en Nueva York, donde él presentó el video de su organización titulado Moojk/ Maíz en el Festival de Cine y Video Indígena de 1995 — uno de los años en los que fui la coordinadora de la selección de los programas de América Latina-. En esta ocasión, sin embargo, me encontraba por primera vez en su comunidad.

Me desperté el día siguiente a las seis de la mañana con el sonido del cuerno que llamaba todos al tequio mezclados con los sonidos cotidianos de la mañana: el cantar de los gallos y la música variada de diferentes programas de radio. Mientras dejábamos el centro de Tama, pasando por caminos angostos entre pequeñas casas y patios, el humo de las fogatas en el sitio del tequio estaba saliendo del valle. Gente de todas las edades - aunque en su mayoría adultos y ancianos- que cargaban herramientas rústicas de cultivo, llegaron a la veredita en que me encontraba hasta que formamos una corriente que fluía bajando en fila hacia el río. Los campos ya se encontraban en gran y organizada actividad. Filas de gente arando rítmicamente los 
campos recién chapeados, que parecían extenderse hasta donde llegaba la vista; un buey con su arado hacía hábilmente surcos por donde ya había pasado la gente. La mezcla de olores, sonidos y texturas colmaban el ambiente decididamente: pedazos de tierra fresca, desechos crujientes y humo en fogatas masivas, bueyes cuyo sudor salía como vapor de su cuerpo en el aire fresco de la mañana, los látigos y las canciones de los aradores, el agua borboteando alrededor de las rocas en el cauce del río. Fue una introducción espectacular y sensual a Tama y al significado de la comunidad del tequio. Las imágenes del tequio grabadas en video emergen como propuestas visuales clave de la vida colectiva empleadas por Radio y Video Tamix para ubicarse a sí mismos como una organización comunitaria.

\section{De la Casa del Pueblo a la Radio y Video Tamix}

El programa de video del INI desempeñó un papel crucial en el desarrollo de Radio y Video Tamix, la organización de comunicadores de Tama. Cuando los miembros de Tamix participaron en el programa del INI, la organización ya se había transformado a partir de un grupo libre de maestros de escuela que trataban de entretenerse a sí mismos y a su comunidad, donde se organizaban concursos y bailes en un centro cultural llamado la "Casa del Pueblo" con fondos del estado y un modesto presupuesto anual de 10,000 pesos en 1989. La Casa del Pueblo funcionaba también como un centro de producción radiofónico para la estación regional indígena del INI que se encontraba en el pueblo zapoteco de Guelatao de Juárez. En 1990 el grupo contactó a un paisano emigrado a los Estados Unidos para que les trajera una cámara de video, la cual utilizaron para grabar sus sesiones de producción radiofónica, visitas oficiales, fiestas patronales y las principales actividades de la municipalidad como el "cambio de autoridades", celebrado el primero de enero de cada año. En 1992, dos miembros de la Casa del Pueblo participaron en el segundo taller nacional de video del INI, y poco después la organización anunció su nuevo proyecto: la "Radio y Video Tamix" — seguidamente se abreviará Tamix.

El taller de producción de video del INI no sólo transfirió equipo de producción de video y conocimientos básicos para su uso, sino también el discurso institucional acerca del papel de la cultura en el desarrollo de las comunidades indígenas y la idea sobre cómo la representación de sí mismos por medio del video podía reforzar la identidad de la comunidad. $\mathrm{Si}$, como lo señaló Clemente, al iniciar la Casa del Pueblo no se hablaba de "rescate cultural", en 1992, cuando Tamix imprimió su primer folleto promocional, ya se encontraba como un objetivo "primordial" el "rescatar, preservar y promover la cultura mixe por medio de grabaciones y del uso de equipo de video, porque sabemos que la comunicación es un medio para reforzar nuestra identidad" (Tamix, 1992). Como hemos visto en la primera sección, el trabajo social que describe el folleto de Tamix se alcanza con la tecnología misma: viéndose en el espejo electrónico hace que nazca la conciencia de identidad como un aspecto de lucha social. Aunque, en realidad el proceso no es tan directo ni tan sencillo.

La consolidación de Tamix se completó con el "descubrimiento" de un equipo transmisor de televisión. Los conocimientos recién adquiridos en el taller nacional de video, así como el incremento significativo del equipo donado por el INI, les permitió apropiarse de un transmisor abandonado y jamás utilizado. El transmisor había sido originalmente instalado en Tama como parte de una red de retransmisión rural de IMEVISION. Ésta empezó como un proyecto del Estado que fue privatizado en $1980 \mathrm{y}$ comprado por TV Azteca, una de las redes televisivas comerciales más grandes de México. El transmisor de 10 watts manda la señal de Tamix a un área limitada 
—máximo 5 kilómetros—, pero debido a que su frecuencia se encuentra prefijada en el canal 12, su señal interrumpe la programación de TV Azteca, no sólo una de las señales más fuertes que llegan a Tama, sino también uno de los recursos más populares para acceder a telenovelas y noticias.

\section{"TV Tamix Presenta": Estableciendo las bases}

TV Tamix inicia sus transmisiones televisivas con una serie de agradecimientos a las autoridades simbólicas y reales más importantes, empezando por la montaña sagrada, la nación mexicana a la que pertenecen y la comunidad. Esta serie de pedidos representan un esfuerzo por insertar el proyecto de televisión dentro de la comunidad. Cuando inicia el himno nacional mexicano, tomas panorámicas y el uso del zoom introducen al sagrado Zempoatepetl, uno de los picos más altos en Oaxaca y el lugar en el cual según la leyenda nació de un huevo la deidad mixe, el Rey Kong Hoy. Los ocho versos del himno se escuchan mientras se ven imágenes de la comunidad en algunos momentos muy concurridos del tequio y en ceremonias que dan la bienvenida al nuevo consejo de gobierno. Una enorme piedra es soltada de un lado de la montaña mientras que miembros de la comunidad abren a mano un nuevo camino. Una estructura de concreto de dos pisos del mercado está casi lista mientras los residentes acarrean pesados baldes de concreto por las delgadas rampas que van al techo. Una multitud da la bienvenida al recién elegido consejo con velas y flores y desfila bajo los arcos del palacio municipal y la bandera mexicana. Cuando se escucha el himno mixe que prosigue, los productores de la televisión Tamix se presentan mientras trasmiten su señal desde el sitio original en la escuela secundaria, y muestran su estudio, la forma en que graban los programas de radio y cómo editan video con el equipo donado. Por lo tanto, la autonomía mixe, evocada por el himno mixe, está visualmente ligada al uso de equipo de alta tecnología, y en el proceso se propone también una identidad local que abraza la tecnología moderna.

El folleto de la organización ubica firmemente a TV Tamix dentro de la comunidad, pero se le subordina al reconocer que su "máxima autoridad es la asamblea general de los comuneros o de los propietarios" (Tamix, 1992). En especial, evocan al tequio para ejemplificar su posición como un proyecto de comunidad y adoptan el término "espacio sagrado" para señalar la importancia simbólica — significado simbólico- de la estación, para indicar que el hacer video y televisión es tan sagrado como el tequio. Una connotación que le agrada a algunos miembros del programa de TMA, ya que ejemplifica una indigenización positiva de la tecnología presentada por el INI. Además, hacen un listado con los nombres de los miembros y se describen como "personas cuya lengua materna es el mixe y que prestan su servicio voluntariamente de una manera considerada como tequio" (Tamix, 1992).

La presentación de la estación continúa después del himno mixe con varias secuencias acompañadas por una narración que, como su folleto, está en castellano e imita promocionales de estaciones de radio y televisión comerciales: "Porque sabemos que la comunicación es una herramienta fundamental para el desarrollo y fortalecimiento de nuestra cultura e identidad. ¿Quiénes somos? ¡Radio y Video Tamix de Tamazulapam Mixe transmitiendo con 10 watts de potencia! La nueva forma de ver y escuchar, los sábados a las cuatro de la tarde por el canal 12 en sus aparatos receptores". La parte final de la presentación es una canción local dedicada a las mujeres de Tama y a sus trajes. Mientras que existe conciencia entre los residentes de Tama del papel que tiene el traje tradicional para mostrar autenticidad a las audiencias foráneas, las tomas de mujeres que trabajan en el campo, preparando comida y ofrendas religiosas, conectan claramente a la estación 
con una de las características culturales únicas y más visuales de Tama. Por medio de esta secuencia, la televisión Tamix confiere respeto no sólo a las mujeres y a los ancianos - grupos sociales ausentes en la organización — sino también al panteón de deidades a las que las mujeres suplican por medio de prácticas diarias de ofrendas y sacrificios. Cada sección de la introducción está separada con una toma fija de "barras de colores" culturales de Tamix, utilizando el rebozo de las mujeres, como un traslape simbólico divertido.

Luego de esta serie de agradecimientos a la nación mexicana, a la comunidad y a las deidades, la transmisión de la televisión Tamix continua con una variedad de programas que consisten en su mayoría en grabaciones originales poco editadas de los asuntos del pueblo, como graduaciones escolares y visitas de los oficiales del gobierno, aunque ocasionalmente lanzan al aire algún documental del INI. Entre 1992 y 1995 , Tamix, movió la antena del patio de la escuela y la erigió nuevamente en el techo del palacio municipal de Tama desde donde se ha vuelto a transmitir. Durante este tiempo, varios jóvenes del poblado —en especial el hermano menor de Clemente, Gilberto, y su primo Esteban, que habían llegado recientemente de Veracruz - se entrenaron en el Centro de Video Indígena del INI de la ciudad de Oaxaca y se hicieron miembros activos de Tamix. Hacia finales de 1998, Tamix estaba en el aire con un nuevo programa cuyo tema versaba sobre los niños: "Hoy en la comunidad". Programa producido, en parte, con fondos de una institución nacional para infantes. Creado por iniciativa personal de Esteban, "Hoy en la comunidad", "es un espacio abierto para todos los miembros de la comunidad interesados en hablar y reflexionar sobre eventos que ocurren en el desarrollo de nuestro pueblo Ayuuk" (Tamix, 2000).

\section{"Hoy en la Comunidad": Ampliación de las bases}

Algunas tomas del tequio son aún empleadas en la secuencia de presentación de "Hoy en la Comunidad", pero ahora música rock acompaña las imágenes, en vez de himnos o canciones tradicionales, y el estilo de los encuadres es menos tentativo, más intencionado. En lugar de enfocarse en imágenes de la comunidad, la presentación del programa es un montaje de momentos vividos en el estudio de la televisión Tamix. Diferencias notables en estilo y tono de la presentación anterior reflejan desacuerdos más profundos entre la "generación" de los miembros fundadores y los más jóvenes, acerca de lo que constituye una programación apropiada y sobre el papel que deben de jugar los medios de comunicación en la comunidad. Sus programas tratan, de hecho, de lo que sucede en el pueblo. Un día, el Estado patrocinó una campaña sobre higiene dental, lo que impulsó a Gilberto y Esteban a alistar los niños de la primaria para explorar sus prácticas de higiene; y en la noche, en un programa de información con representantes de la organización Alcohólicos Anónimos, editaron un corto llamado "Mareados con la Chela". Este corto empieza con la actuación de una borrachera de cerveza y sigue con tomas - reales y actuadas - de miembros de la comunidad que se encuentran inconscientes, tirados en el suelo después de la fiesta patronal. Una música melancólica de violín clásico dramatiza la tragedia del alcoholismo en Tama, lo que se acepta socialmente como un problema en la comunidad.

Clemente no estaba de acuerdo con lo que la generación más joven de videastas considera como material "indígena" y "cultural." En su opinión, los videos indígenas en castellano no son verdaderamente indígenas y también se opone a los programas de Esteban, argumentando que éstos no enfatizan los aspectos estrictamente "culturales" que él considera 
importantes o apropiados. Tanto Gilberto como Esteban, sin embargo, piensan que su programación debe ser actual, acerca de lo que está pasando en su poblado, y "Hoy en la comunidad" pone de manifiesto sus esfuerzos por sustraer la programación de Tamix del control de Clemente, para hacerla más "neutral", como ellos entienden que deberían ser los medios de comunicación. Para la generación más joven, se está viviendo un periodo de cambios fuertes y sostienen que la definición de Clemente sobre la cultura indígena es muy rígida y exclusiva. En la opinión de estos jóvenes, su mejor espectáculo fue una tarde de música y entrevistas con el grupo de rock "Ruina Jade" del Distrito Federal. Aún bajo el "riesgo de serinauténtico," para usar un término que Levi y Dean utilizan en su reciente libro sobre los derechos indígenas (2003), Gilberto y Esteban enfatizan una versión más constructiva o menos esencial de la identidad indígena ante la versión más conservadora de Clemente que, no por casualidad, refleja el uso de la cultura como folclor que maneja el INI. Los desacuerdos sobre el contenido generan nuevos debates acerca de la identidad cultural en la comunidad y demuestran la pluralidad de posiciones que se constituyen en el video indígena.

\section{Crisis en la organización}

Como organización, Tamix resuelve estos desacuerdos al permitir que cada miembro desarrolle su propio proyecto. Sin embargo, hay conflictos más profundos entre la organización y la comunidad que han sido más difíciles de resolver. En 1996, Radio y Video Tamix ganó una beca del Fondo Estatal para la Cultura y las Artes (FOESCA) de Oaxaca de unos 80000 pesos y una beca de 12000 dólares de las Fundaciones MacArthur y Rockefeller, lo que significó un incremento extraordinario de su presupuesto anterior. El reconocimiento internacional a la organización y, aún más importante, el colchón de seguridad económica desconocido hasta ahora, fueron rápidamente ensombrecidos por el incremento de una actitud hostil hacia ellos por parte de miembros de su comunidad. A pesar de los esfuerzos por arraigar el proyecto de representación audiovisual de la comunidad por medio de la evocación visual de usos colectivos, Tamix fue acusada por miembros de la comunidad de corrupción y evasión fiscal. Al parecer, el espejo electrónico y la fe del grupo en la supuesta capacidad del video de representar con transparencia no fueron suficiente para convencer al pueblo de su proyecto. Estas acusaciones culminaron con la expulsión de los comunicadores y su equipo del palacio municipal, un acontecimiento que efectivamente dividió a la Casa del Pueblo y a Radio y Video Tamix en distintas organizaciones.

El grupo perdió a varios de sus miembros durante la separación y las transmisiones de televisión casi se detuvieron durante 1997, pues Tamix no clausuró su programación por completo. De hecho, el conflicto generó oportunidades inesperadas para que miembros jóvenes asumieran papeles más activos. Menos vulnerables a la crítica de la comunidad por su juventud — tenían cerca de 18 años en ese periodo—- Gilberto y Esteban, efectivamente mantuvieron a la organización con vida. A diferencia de los miembros fundadores de la Casa del Pueblo que eran maestros de profesión, ellos no tenían otros trabajos o familias que mantener. Además, Gilberto y Esteban sentían que habían "crecido" en Tamix y que no podían dejar este proyecto "así nomás". Tamix reestableció sus operaciones en un nuevo local en 1997 y gastó gran parte de las dos becas para renovar el edificio y equipar el nuevo estudio de televisión. Al llegar a Tama por el camino pavimentado desde la ciudad de Oaxaca, resalta a la vista el que es el letrero más visible del pueblo. Anunciándose sobre los letreros coloridos de la publicidad de cerveza en unas paredes alrededor del pueblo, TV T-A-M-I-X también se encuentra pintado sobre la fachada del estudio, reclamando físicamente una posición central en la comunidad, imposible de ignorar. 
Cambios en la programación televisiva y una nueva producción de video se hicieron manifiestos en la actividad del grupo en 1997 y gran parte de 1998, lo que reflejó tanto sus obligaciones hacia las instituciones donantes como una relación más cuidadosa con la comunidad. Sin embargo, hacia finales de 1998, cuando el conflicto agrario entre Tama y Tlahui se acentuó, algunos miembros de Tamix pudieron trabajar en cooperación con el consejo municipal por primera vez en casi dos años. Se le pidió al grupo grabar los encuentros de negociación y varios días de tequio, durante los cuales se consolidó la frontera municipal de Tama con mojoneras grandes, mientras áreas extensas de tierra en disputa fueron chapeadas para el cultivo. El primer tequio al que asistí en Tama era el segundo de una serie de tequios que la comunidad había dedicado al reclamo de facto de esta tierra en conflicto. A pesar de esta legitimación de TV Tamix por parte del consejo municipal, varios comuneros pidieron a Gilberto y Esteban que dejaran de grabar y que agarraran una coa, lo que en otras palabras significaba que hicieran un trabajo "verdadero". El tequio no es sólo uno de los símbolos más importantes de la vida de la comunidad colectiva — como enfatiza también TV Tamix en su programación — sino es también obligatorio en Tama y por ello un asunto serio. Desde 1998, el tequio es, además, reconocido legalmente por la constitución del estado de Oaxaca. Un comunero que no asiste al tequio es multado o se le encierra un día en la cárcel local. El filmar, ante los ojos de muchos comuneros, no es un trabajo comunal legítimo y, por lo tanto, no constituye una liberación de tal compromiso. Comparado directamente con el trabajo intensivo de campo, cargar una cámara en el hombro, o peor, en la palma de la mano, no es considerado como trabajo "verdadero" en el sentido físico. Tal trabajo "verdadero" del cultivo del maíz sin duda está profundamente conectado con el sentido de ser mixe. A pesar de que Tamix utiliza imágenes del tequio en sus programas de televisión para ubicarse como grupo comunitario ante la comunidad misma, el acto de grabar el tequio sirvió como una forma de rechazar al grupo y negar la validez de su trabajo.

\section{Fin de la crisis}

La discusión entre los miembros del grupo frente a estos conflictos se centraba en dos planteamientos: por un lado se quería normalizar el trabajo de Radio y Video Tamix como cargo comunal y, por el otro, se planteaba la problemática de "ver la cultura". La posición intermedia de Radio y Video Tamix en la comunidad le proporciona cierta libertad y control de su producción y programación pero también serias desventajas. Clemente enfatizaba a menudo que el video y la televisión de la comunidad deberían ser incorporados al sistema de trabajos de la comunidad o como un servicio requerido por la comunidad, del mismo modo que el participar en la banda filarmónica municipal. De esta manera, sus actividades serían transparentes para toda la comunidad y Tamix potencialmente tendría recursos fiscales y humanos más seguros. Además, si el trabajo de producir medios de comunicación en la comunidad fuera regulado y percibido como un cargo, desde el punto de vista de los comunicólogos locales, el no ser compensados económicamente por su trabajo se justificaría mejor ya que todos los trabajos comunales son voluntarios. En la actualidad, los jóvenes que se han capacitado en Tamix tienden a abandonar la organización porque sienten que ahí no tienen futuro económico. Por su parte, los veteranos han expresado su frustración cuando los jóvenes capacitados por ellos se han ido en busca de mejores oportunidades económicas. La idea de normalizar dicho trabajo no tuvo eco, como tampoco la tuvo la preocupación que ventiló una mujer de la comunidad acerca de la continuidad de Tamix. Como ella me explicó, la comunidad está 
acostumbrada a que los cargos sean rotados anualmente. Tamix no tiene ese perfil pero ocupa una posición de poder en la comunidad, el poder de representar la comunidad dentro y fuera del pueblo. El hecho de que las mismas personas, e incluso la misma familia, han sido asociadas con Tamix desde el inicio ha fomentado la sospecha de que la organización de comunicadores es un negocio para obtener ganancias personales, no un servicio comunitario.

Los miembros de Tamix, tanto los recién llegados como los fundadores, centran sus esfuerzos en la problemática de representar la cultura en video. Según éstos, Tamix trabaja con medios audiovisuales "para que la gente se vea". El mostrar videos mixe en su propia comunidad es motivado por la convicción de que el verse a sí mismos sirve para estimular el pensamiento crítico y generar procesos reflexivos. De acuerdo con Gilberto: "Cuando hablas no te escuchas a ti mismo hasta que alguien te dice lo que dijiste". Aquí el "espejo electrónico" que introdujo el INI se transformó en una herramienta para promover un cambio social basado en la autorreflexión. Sin duda, el video —y más la televisión local— tiene éxito como película casera - a los miembros de la comunidad les gusta verse en televisión- pero el proceso de producción permanece opaco, y por lo tanto, genera sospechas en la mayoría de los miembros de la comunidad. En palabras de otro veterano de Tamix, Rodrigo, la gente no valora lo que hacen porque "no ven la cultura" como verían la construcción de una casa. La gente sabe lo que cuesta en trabajo y dinero la construcción de una casa, el hacerla "bien" y "bonita". Sin embargo, explica, no pueden ver hacia dónde va el dinero para una producción de video. Gilberto compara el video con el pan: "el video no es como hacer pan donde el producto es visible y todos lo compran". En otras palabras, el proyecto de Tamix hace la cultura visible en video, pero la producción misma del video permanece invisible.
Como tantos otros activistas indígenas, los productores de Radio y Video Tamix tratan de fomentar cambios en su comunidad. Clemente con frecuencia decía que él quería que su gente "despertara" para poder cuestionarse y criticar, para darse cuenta de lo que tienen. Su toque personal se basa en el humor y la espontaneidad que se manifiesta, por ejemplo, cuando coloca los cuernos de venado encima de la videocámara o realiza transmisiones de televisión en broma avisando la llegada de estrellas de rock parisinas al centro de Tama. No obstante, cuando él junto con otros miembros de Tamix abrazaron los programas del gobierno, su proyecto inicial de divertir y despertar a la gente tomó otro rumbo y se transformó en un proyecto de rescate cultural y de reforzamiento de identidad.

Si volvemos por un momento a la etapa de los talleres nacionales de producción de video del programa de TMA, recordaremos que los maestros se apoyaban en la idea del espejo electrónico para presentar y enseñar el video como una tecnología transparente. A la vez propiciaban un activismo social con base en la representación cultural y la autorreflexión con la misma lógica que luego utilizaban los miembros de Tamix cuando explicaron que el video era un espacio que generaba reflexión. Hay ejemplos muy claros sobre cómo el verse en video motiva directamente un proceso tendiente a retomar ritos o costumbres ya perdidos (Aufderheide, 1995). Sin embargo, el problema que articula Rodrigo, de que la gente no "ve la cultura" tiene que ver con el poner una sobrecarga de responsabilidad en el medio mismo — una fe exagerada en el "espejo electrónico- en vez de centrar su atención en procesos sociales mucho más complejos, que toman mucho más tiempo que el acto de grabar y proyectar una imagen en video. Tanto los maestros del programa de TMA como los miembros de Tamix buscan maneras de insertar o traducir culturalmente el "video indígena" al "mundo indígena"; los primeros, con el uso de la técnica del "espejo electrónico"; y los 
segundos, al presentarse bajo los poderes del mundo mixe y al enfatizar el colectivismo y la utilidad de ciertos toques visuales locales, aunque ambos esfuerzos enfrentan serios obstáculos sociales. Lo que quiero señalar con esta reflexión es que al concebir el video indígena como práctica social, más que como una mera tecnología, nos damos cuenta que no es algo directo, transparente o dado. El video indígena se construye como la identidad cultural indígena, a través de prácticas y relaciones sociales complejas y propone una posición particular, parcial y siempre política. Los individuos, instituciones e intereses involucrados en la producción del video indígena demuestran cómo, hasta las identidades basadas en una ubicación geográfica, se producen pluralmente por medio de arenas múltiples y sobrepuestas que incluyen comunidades locales, centros regionales, burocracias nacionales del gobierno y redes transnacionales, como los festivales de cine y video indígena, ámbito desde el cual empecé a conocer y apoyar a los realizadores indígenas de México. Un resultado de este reconocimiento es que la hibridad no alcanza a describir de manera adecuada al video indígena como proceso y forma social: éste se encuentra en un espacio analítico mucho más allá, en lo múltiple y plural. En el proceso, este análisis del video indígena puede potencialmente conducir el discurso de la identidad indígena más allá de la interacción entre participación política y autenticidad que Levi y Dean, (2003) usan para enmarcar su discusión de los derechos indígenas — y más allá de la hibridad — lo que libera la identidad indígena de la garra de la autenticidad. La autorrepresentación indígena es algo central para las luchas más amplias de autodeterminación y autonomía, como los desafortunados pero aún valiosos Acuerdos de San Andrés claramente señalan. Esta breve y parcial historia del video indígena y de Radio y Video Tamix, demuestra que el proceso de articular identidades indígenas "en casa" y dentro de los circuitos discursivos fuera de la comunidad, es algo complejo y que debemos mantener esa complejidad y pluralidad en nuestra comprensión de tales procesos sociales tan dinámicos.

\section{Notas}

${ }^{1}$ La autonomía indígena es un tema discutido y vivido en formas muy variadas. En general me refiero a un proceso político y organizado que tiene ramas articuladas y desarticuladas con un movimiento social que se constituye en ámbitos locales, regionales, nacionales y globales, dentro del cual los principales protagonistas son activistas indígenas que ejercen su derecho a la autodeterminación. La autodeterminación también es un concepto muy discutido y básicamente concierne los derechos de definir su propia cultura, gobierno y el manejo de los recursos naturales (véase Stavenhagen, 1990, 1992; y Van Cott, 1994, 2001).

${ }^{2}$ En mayo de 2003, el presidente mexicano, Vicente Fox Quesada anunció el fin del INI después de 54 años de existencia; o más precisamente la transformación legal de esta institución en Comisión Nacional para el Desarrollo de los Pueblos Indígenas (CONADEPI). En el presente artículo me refiero al llamado "video indígena" como un proyecto del INI dentro de un marco nacional e histórico específico y no a otros proyectos comparables que han existido en otras partes de América Latina y el mundo, como son Video Nas Aldes ("Video en las Aldeas") (Aufderheide, 1995) y el Proyecto de Video Kayapo (Turner, 1991) en Brasil, por mencionar dos de los casos más conocidos.

${ }^{3}$ Cabe señalar que el INI llevaba más de quince años desarrollando un sistema nacional de radios indígenas cuando empezó el proyecto de TMA. De hecho, varios de los videastas indígenas que colaboraron en mi investigación llegaron al video después de haber trabajado en la radio. Sin embargo, el proyecto de video surgió de diferentes iniciativas y con metas menos definidas. La diferencia que más llama la atención en comparación con la radio, es la falta de una red nacional de video-difusión. El antecedente más relevante y directo del proyecto de video indígena del INI no son las radios, sino un proyecto de cine- 8 de corta duración que involucró a un grupo de tejedoras ikood de San Mateo del Mar, Oaxaca, en 1985 y del cual salió el documental Tejiendo Mary Viento (INI, 1986).

${ }^{4}$ Aunque el proyecto de TMA surgió de manera autónoma o independiente, es decir, las personas involucradas en su desarrollo pensaron que estaban creando algo completamente nuevo, existen similitudes importantes con otros proyectos 
ya encaminados en la década de 1980 como, por ejemplo, el Proyecto de Video Kayapo en la Amazonia de Brasil. De acuerdo con un argumento central de Terrence Turner (1991) sobre esta experiencia, podemos afirmar que el proyecto de TMA demuestra igualmente una estrecha conexión entre el video o la representación visual y la objetivización de la cultura.

${ }^{5}$ Todos los actores en esta historia tienen vidas relativamente públicas en términos de su participación en el proyecto de video indígena, algunos de ellos más que otros. En el presente trabajo he decidido usar seudónimos para los actores que tienen una vida menos pública.

${ }^{6}$ Es una dinámica difícil, como afirma también Turner (1991) en su relato de los problemas con el video y el poder local entre los kayapo.

\section{Bibliografía}

Aufderheide, Patricia, 1995, "The Video in the Villages Project: Videomaking with and by Brazilian Indians", Visual Anthropology Review, Vol. 11, Núm. 2, pp. 83-93.

Becerril, Alberto (realizador), 1986, Tejiendo Mary Viento. La Vida de una Familia Ikood, documental, formato Super-8, duración de 23 minutos, INI, Oaxaca.

Bhaba, Homi, 1994, The Location of Culture, Routledge, New York.

Centro de Video Indígena del InI, 1996, Oaxaca, México.

Cremoux, Daniela, 1997, Video Indígena. Dos Casos en la Sierra Mixe, Tesis de Licenciatura, Universidad Intercontinental, México.

Cruz, Carlos, 2000, Entrevista, México.

García, Juan José, 2000, Entrevista, Ciudad de Oaxaca.

García Canclini, Néstor, 1989, Culturas Híbridas: Estrategias para entrary salir de la modernidad, Consejo Nacional para la Cultura y las Artes y Editorial Grijalbo, México.

Ginsburg, Faye, 1993, "Aboriginal Media and the Australian Imaginary”, Public Culture, Vol. 5, Núm. 3, pp. 557-578.

Hall, Stuart, 1996, "Introduction: Who Needs Identity?", en S. Hall y P. du Gay (eds.), Questions of Cultural Identity, Sage Publications, Londres, pp. 1-17.

Julián Caballero, Emigdio, 1994, "La T.V. No Es Realidad", en Muestra Interamericana de Videoastas Indígenas, pp. 8-9, INI, México.

Kearney, Michael y Stefano Varese, 1995, “Latin America's Indigenous Peoples: Changing Identities and Forms of
Resistance", en S. Halebsky y R. L. Harris (eds.), Capital, Power and Inequality in Latin America, Westview Press, Boulder, pp. 207-231.

Kuroda, Etzuko, 1984, Under Mt. Zempoaltépetl: Highland Mixe Society and Ritual, Museo Nacional de Etnología, Osaka, Japón.

Levi, Jerome M. y Bartholomew Dean, 2003, "Introduction”, en Bartholomew Dean y Jerome M. Levi (eds.), At the Risk of Being Heard: Identity, Indigenous Rights and Postcolonial States, University of Michigan Press, Ann Arbor, pp. 1-44.

Lupone, Luis y Teófila Palafox, 1987, Tejiendo Mary Viento. La Vida de una Familia Ikood, documental, formato Super-8, duración de 23 minutos, INI, Oaxaca.

Radio y Video Tamix, 1992, Folleto de la organización, Tamazulapam Espíritu Santo, Oaxaca.

Radio y Video Tamix, 2000, Folleto de la organización, Tamazulapam Espíritu Santo, Oaxaca.

Redfield, Robert, 1968, The Folk Culture of Yucatan, University of Chicago Press, Chicago.

Stavenhagen, Rodolfo, 1990, "Derecho Consuetudinario Indígena en America Latina", en R. Stavenhagen y D. Iturralde (eds.), Entre la ley y la costumbre, Instituto Indigenista Interamericano, México, pp. 27-46.

—, 1992, "Challenging the Nation-State in Latin America", Journal of International Affairs, Vol. 34, Núm. 2, pp. 421-440.

Turner, Terrence, 1991, “The Social Dynamics of Video Media in an Indigenous Society: The Cultural Meaning and Personal Politics of Video-making in Kayapo Communities," en Visual Anthropology Review, Vol. 7, Núm. 2, pp. 68-72.

Van Cott, Donna Lee, 1994, "Indigenous Peoples and Democracy: Issues for Policymakers", en D. L. Van Cott (ed.), Indigenous Peoples and Democracy in Latin America, St. Martin's Press en asociación con The Inter-American Dialogue, New York. pp. 1-27.

Van Cott, Donna Lee, 2001, "Explaining Ethnic Autonomy Regimes in Latin America", Studies in Comparative International Development, Vol. 35, Núm. 4, pp. 30-58.

Worth, Sol y John Adair, 1997, Through Navajo Eyes: An Exploration in Film Communication and Anthropology, University of New Mexico Press, Albuquerque. 


\title{
MÁs ALlÁ de la HiBRIDAD: LOS MEDIOS TELEVISIVOS Y LA PRODUCCIÓN DE IDENTIdades Indígenas en OAXaCA, MÉxico
}

\author{
Erica Cusi Wortham*
}

\section{TV Tamix sale al aire}

$\mathrm{E}$ 128 de noviembre de 1992, algo fuera de lo normal sucedió en el municipio Mixe de Tamazulapam del Espíritu Santo, Oaxaca. El mercado estaba cerrando, los comerciantes del valle empacaban para irse a casa y los otros habitantes hacían sus quehaceres cotidianos: las mujeres desplumaban gallinas, los niños disfrutaban paletas y dulces comprados en el mercado y los hombres disfrutaban de un baño. Los televisores emitían los noticieros, deportes o telenovelas favoritas, cuando la señal fue interrumpida y dos rostros familiares aparecieron en la pantalla. Armados con micrófonos y audífonos, dos profesores de la escuela primaria de Tamazulapam saludaron a la comunidad en castellano y ayuuk, a la vez que anunciaron una nueva estación televisiva: "¡Canal 12, TV Tamix de Tamazulapam!” Reloj en mano, uno de ellos repitió el día y la hora exacta para no dejar ninguna duda en las mentes de los televidentes de que se estaba trasmitiendo en vivo. Al principio nadie creía que la señal venía en realidad de Tamazulapam misma y se preguntaban cómo estos locos habían podido introducirse en un estudio televisivo en la ciudad de

${ }^{*}$ Erica Cusi Wortham, Investigadora huésped, Departamento de Antropología, Universidad de California, San Diego.
Oaxaca o en el Distrito Federal. Sin embargo, un niño reconoció el escenario - el patio de su escuela donde una antena había sido abandonada por años-y corrió por la calle para descubrir el equipo televisivo en acción: “¡Miren, miren! ¡Están en la secundaria!”.

Por primera vez en aproximadamente quince años, cuando los residentes de Tamazulapam empezaron a comprar televisores, los programas se relacionaban de manera directa a su identidad como gente indígena.

Los medios indígenas, entendidos como conocimiento tradicional plasmado en la tecnología moderna, de alguna manera ejemplifican una forma cultural híbrida. Como señala Homi Bhaba (1994), el concepto de la "hibridad" en su aplicación a las sociedades y los discuros poscoloniales nos permite entender la ambivalencia de la autoridad colonial y su constante subversión por parte de los colonizados como procesos tanto históricos como sociales. Néstor García Canclini (1989) refiere la "hibridez" para analizar la vitalidad del mestizaje en la cultura popular. Resulta útil esta noción para profundizar en los frecuentes estrechos entendimientos en torno a las identidades indígenas contemporáneas. Investigadores como Faye Ginsburg (1993) y Stuart Hall (1996) hacen percatarnos del cambio cultural y la formación de la identidad como prácticas autoconscientes, a diferencia de etnógrafos 
anteriores quienes estaban preocupados por el "cambio cultural" impuesto en las comunidades desde afuera (Redfield, 1968; Kuroda, 1984). No obstante, con el concepto de hibridez corremos el riesgo de caer en falsos dualismos: tradicional/moderno, urbano/rural o alternativo/masivo. Dualismos que no reflejan adecuadamente las facetas, los agentes y los múltiples intereses relacionados con la producción y circulación de identidades indígenas en video. Es necesario plantearse la cuestión en términos más abarcadores que el de hibridez, para reconocer que las identidades indígenas se producen pluralmente a través de relaciones sociales que involucran, en este caso, a agencias de gobierno, maestros de video independientes, etnógrafos, activistas, patrocinadores, programadores y creadores de video indígena, lo que muestra que las identidades indígenas son algo complejo, contestado y no reductible.

El presente estudio centra su reflexión en los esfuerzos claros, visibles y autoconscientes para lograr un cambio social a través del desarrollo del llamado "video indígena," fenómeno multifacético que representa tanto un proceso como una forma social dentro de la cual están profundamente entrelazados el patrocinio del estado y la autonomía indígena. ${ }^{1}$ Apreciar la pluralidad nos permite reconocer nuestra propia complicidad en la movilización política de categorías como cultura e identidad. Mi propósito no es reconocer el trabajo de los antropólogos o negar la conexión real de la identidad a las vidas y patrones sociales y culturales - ni a los lugares e historias específicas - sino reconocer tres asuntos relacionados entre sí: 1) que como estudiosos de la cultura, compartimos el campo de producción de conocimientos con aquellos a quienes representamos; 2) que dentro de la identidad cultural hay un complejo de intereses actuando en su consolidación y representación; 3) que la identidad cultural —y su representación visual- es una herramienta construida y fundamentalmente política que se utiliza en luchas de cambio social. Estos aspectos se relacionan en el presente estudio con una discusión sobre cómo el video es introducido a comunicólogos indígenas al interior de las dinámicas sociales de una comunidad mixe.

El "video indígena" como tal llega a Tamazulapam del Espíritu Santo — a partir de aquí lo abreviaré como Tama - en 1992 por medio de un programa del Instituto Nacional Indigenista - INI - que presenta al video como una herramienta para reforzar la identidad cultural. $^{2}$ En la siguiente sección — titulada Enseñando video indígena - hablaré de cómo dicho video indígena se desarrolló de manera particular por los instructores del programa quienes buscaban fomentar una propuesta visual "auténtica" indígena, cuando en realidad estaban desarrollando activismo cultural. La manera de introducir el video - como un "espejo electrónico" - crea ciertas expectativas que subvierten el potencial del video indígena en la comunidad. En la segunda sección: Radio y Video Tamix, resumo brevemente los diez años de historia de un grupo de comunicadores indígenas, desde sus inicios en el proyecto estatal "Casa del Pueblo", su consolidación como estación de televisión local, hasta una crisis que deja al grupo sin una posición clara frente a su propia comunidad. En relación con la historia de la Radio y Video Tamix analizo algunas de las estrategias de implantación - cómo miembros del grupo tratan de insertar el video indígena dentro de la comunidad por medio de la evocación de modismos de la vida colectiva-, así como ciertas tensiones y contradicciones surgidas en la producción del video indígena que muestran la complejidad identitaria en el proceso de producción de sus programas. 


\section{Enseñanza del video indígena: en busca de alteridad estética y al encuentro de solidaridad política}

Fundado enteramente por el presidente Carlos Salinas de Gortari y su programa de "Solidaridad", el programa de video del INI capacitó aproximadamente a 85 indígenas que representaban a 37 organizaciones distintas de todo México por medio de una serie de talleres de video nacionales que se organizaron anualmente de 1990 hasta 1994 como parte fundamental del entonces nuevo programa "Transferencia de Medios Audiovisuales a Comunidades y Organizaciones Indígenas" — TMA(Cremoux, 1997). ${ }^{3}$ El título del programa indica la amplia iniciativa con que se inició el proyecto por el entonces director general del INI, el antropólogo Arturo Warman, de entregar o "transferir" funciones y recursos institucionales a manos indígenas. Los talleres nacionales de capacitación duraron de seis a ocho semanas y cubrieron lo básico de la preproducción — cómo concebir y organizar un video-, producción - técnica básica de usos de la cámara, encuadramiento y movimiento-y edición — cómo poner imágenes o secuencias juntas para contar una historia- Al final de cada taller, el INI daba a cada organización participante un paquete de producción de video completo, uno de los pocos ejemplos de transferencia "sólida" durante el periodo de Warman. Cientos de indígenas han sido entrenados desde la fase inicial de los talleres nacionales por medio de una serie de Centros de Video Indígena establecidos en varios estados de la república como segunda fase del programa de TMA, aunque los fondos para el programa han disminuido poco a poco desde 1994. Por medio del programa, miles de horas de videocintas han sido grabadas en y acerca de comunidades indígenas de México y se han editado cientos de programas. Éstos refieren temas tan diversos como la espiritualidad indígena o el SIDA, y circulan dentro y fuera del ambiente indígena. Mientras algunos programas son videoclips musicales y otros son ficciones cortas, los documentales realistas constituyen el género dominante del "video indígena." Estos videos se proyectan en gran variedad de ambientes - que a su vez representan la extensión de relaciones sociales en las cuales se inserta el video indígena-lo cual incluye comunidades indígenas — en ambientes familiares o domésticos y otros espacios colectivos como salas de cine improvisadas-, giras rurales y urbanas organizadas por el INI y por organizaciones no gubernamentales, festivales de cine y video internacionales, museos etnográficos y de arte y, de manera limitada, en televisión y cablevisión en Francia, México y Estados Unidos.

El programa de video del INI fue concebido en la Ciudad de México en las oficinas del Archivo Etnográfico Audiovisual que estaban en ese momento bajo la dirección del etnógrafo mexicano y también cineasta, Alfonso Muñoz. ${ }^{4}$ No obstante, el programa realmente fue desarrollado por tres profesionales de los medios de comunicación - personas urbanas y no indígenas quienes tenían un escepticismo saludable respecto de los proyectos del gobierno- durante los talleres mismos. La metodología de enseñanza a los maestros capacitadores se desarrolló sobre la marcha durante el trabajo y de una manera autorreflexiva e intuitiva. Su acercamiento incluía aspectos técnicos de producción y edición, así como el fomento de una perspectiva crítica hacia los medios en general. Los aspectos técnicos incluían algo de traducción y esfuerzos encaminados a que los alumnos le perdieran el miedo a la tecnología. Sin embargo, los maestros percibieron entre los participantes de los talleres el sentimiento de que la producción del video estaba simplemente más allá de su alcance. Además, no ayudaba el hecho de que toda la información sobre los equipos estuviera en inglés. Unos cuantos términos técnicos fueron traducidos al castellano como "balance de blanco" para "white balance" mientras que otros claramente no 
necesitaban traducción, como "focus," o eran usados en inglés como "zoom" y "play." En especial, el término "videasta" presentaba a los maestros dilemas de imposición foránea, y buscaron títulos más "orgánicos" como "creador de imágenes". El punto central era la percepción de que el programa de video estaba potencialmente creando artistas individuales o, como dijo el maestro responsable de enseñar producción, Carlos Cruz, "seres desvinculados", moldeados en sí mismos a pesar de la misión del programa de reforzar la solidaridad de la comunidad (Cruz, 2000). ${ }^{5}$

Detrás de lo que Cruz llamó su metodología de enseñanza "maravillosamente intuitiva" (Cruz, 2000) estaba un compromiso para facilitar la creación de un "idioma visual indígena" o al menos el de proveer las condiciones para que éste emergiera. De forma pragmática, este compromiso se tradujo en un intento de abstenerse de imponer convenciones estilísticas occidentales para permitir la emergencia de las visiones o el idioma visual de los capacitados. Los instructores constantemente se cuestionaban a sí mismos si ellos estaban, en efecto, reproduciendo una manera peculiar de ver al mundo, pero fueron forzados a reconocer que el cuestionamiento constante confundía a quienes se capacitaban, e impedía abordar los cuestionamientos estéticos. Como me relató Cruz: "nos dimos cuenta de que estábamos generando una confusión profunda, porque cuando los estudiantes escuchaban a los profesores decir 'así funciona pero no lo hagan así'... éstos respondían '¿Lo hacemos o no?' ‘qué diablos me está enseñando?"' (Cruz, 2000). Para el segundo taller, los maestros decidieron seguir un plan de enseñanza más convencional, es decir más parecido a la manera en que ellos mismos habían sido capacitados, con la esperanza de alentar posteriormente, con el análisis y la crítica del trabajo, el inicio de una "propuesta visual indígena".
A pesar de estos deseos, muchos de los capacitados en los talleres produjeron formatos estereotipados de televisión, hubo incluso entrevistadores que ponían atrevidamente el micrófono en la cara del entrevistado y narraciones "en off" mal hechas, y que reproducían lo que recibían de la televisión y radio comercial dominante. Quiero referirme un poco a esta "confusión profunda", porque es aquí donde surgen algunas contradicciones que después entran en juego en Tama. También, se puede entender la frustración de los maestros en relación con la dificultad de fomentar una propuesta indígena emergente con base en su inclinación por el género documental y, en particular, en su uso del término "espejo electrónico".

Al igual que la literatura de testimonio, el documental está estrechamente asociado con el imperativo de dar información histórica revelando realidades ignoradas de la vida de los indígenas, así como de otros grupos sistemáticamente oprimidos (Kearney y Varese, 1995). La preferencia por el documental surge de manera natural ya que los tres maestros tendían por su propio desarrollo profesional a este género. Esta preferencia, junto al hecho de que el programa de TMA nació dentro del Archivo Etnográfico Audiovisual del INI — brazo de producción de documentales etnográficosprefiguró al video indígena dentro del documental. Por otro lado, varios asuntos pragmáticos que tenían que ver con el hecho de grabar en comunidad con pocos recursos, y la necesidad de muchas organizaciones de tener un documento íntegro de sus actividades, llevaron a los maestros a preferir el documental sobre la ficción o, por ejemplo, el ensayo personal. Por estas razones, el documental fue enseñado "naturalmente" como el género de video indígena y continúa como el formato dominante en la mayoría de los medios de producción indígena en México actual —aunque está emergiendo una tendencia hacia el género de ficción.

La preferencia hacia tal género en sí se entiende y no es problemático, pero la combinación del 
documental con la enseñaza de video como un "espejo electrónico" produce ciertas contradicciones interesantes y problemáticas. El "espejo electrónico" consiste en una técnica de video que representa o reproduce la realidad al igual que un espejo en la mano o sobre un muro, de manera inmediata y transparente. El modismo fue una de las estrategias empleadas por los maestros para popularizar al video como algo común e inocuo y, sobre todo, fiel a la realidad. Porque, como explica un videasta mixteco en un breve relato escrito para un folleto de una muestra de video indígena que organizó el INI en 1994, "la TV no es la realidad" (Julián Caballero, 1994) pero, según la lógica del argumento, el video indígena sí lo es. La realidad que refleja es opuesta al mundo de mentiras representadas en los medios de comunicación masiva comercial, un mundo donde la gente indígena no se ve reflejada. El "espejo electrónico" —un aparato supuestamente neutral y transparente- se convierte en una herramienta de lucha bajo la enseñanza de los maestros del programa de TMA, y esta conversión de lo neutral a la lucha no se da sin problemas y contradicciones con otros objetivos del proyecto. El "video indígena" gira sobre la supuesta relación directa y sin mediación del mundo no fílmico, y tal relación no sólo debilita los esfuerzos de los maestros por desarrollar un acercamiento crítico hacia los medios en general, sino también limita su potencial de alentar una "propuesta indígena", tal vez un reto sobrado del experimento que Sol Worth y John Adair trataron de realizar entre los navajo a principios de la década de 1970 (1997). Al final, en la propuesta indígena que sostiene al video indígena - construida mutuamente por los realizadores indígenas y por los maestros activistas - no se trata de un lenguaje visual sino de una posición o postura política que se sustenta en la idea de que al mostrar la cultura en video, se refuerza la identidad cultural y por lo tanto se le puede defender mejor. El video indígena afirma la particularidad cultural a pesar de los procesos de homogeneización cultural promovidos por el proyecto nacional de mestizaje y forma parte de las luchas —organizadas y personales — de autonomía indígena.

La metodología de enseñanza "intuitiva" que se dio al inicio de los talleres nacionales, fue estandarizada en un manual de enseñanza en 1996, escrito de manera colaborativa por varios miembros del equipo del primer Centro de Video Indígena del INI, establecido en la ciudad de Oaxaca en 1994. En éste, se muestra claramente la labor del video indígena.

\footnotetext{
Si las culturas originales del continente americano son diferentes de las de origen europeo y mestizo, entonces la manera de expresarse a sí mismas con imágenes y sonidos no tienen que ser las mismas. La labor que tienen los creadores de video indígena es determinar cómo esta forma de comunicación puede servir para reforzar a sus propios pueblos, constru-yendo sobre sus propios modos de comunicación auditiva y visual como el lenguaje, historias tradicionales, música, símbolos, paisajes y figuras que aparecen en los textiles y en el arte. Las reglas y definiciones existen para ser desafiadas, cuestionadas y finalmente rotas si es necesario. Lo que está escrito aquí puede ser considerado como un punto de partida para que un día los creadores de video indígena puedan escribir sus propios manuales que propongan elementos y conceptos que resultarán en un verdadero video indígena. (CVI, 1996).
}

Un "verdadero" video indígena sigue siendo tan elusivo hoy como lo era a principios de la década de 1990, a pesar de los deseos o pretensiones de los instructores y de algunos creadores de video indígena que pretendían lo contrario. Lo que distingue al video indígena de otros géneros no son los marcadores formales y estéticos, ni los individuos involucrados en su producción —que incluye muchas veces a mestizos como editores y consejeros creativos-, sino una plataforma cultural y política compartida y comprometida. Cuando pregunté al videasta zapoteco Juan 
José García —el segundo director del Centro de Video Indígena en Oaxaca - en el 2000, diez años después del comienzo del proyecto del INI, sobre qué es el video indígena, éste me respondió: "el video indígena no existe” (García, 2000). Me explicó: "Tal vez existe lo que se podría llamar el "video zapoteco" o el "video Juan José," pero el video indígena es más una postura que un género audiovisual claramente diferenciado" (García, 2000). Como tal, esta postura refleja procesos de reclamo, incursiona en un espacio televisual del cual la gente indígena había sido previamente excluida y se construye con diferentes demandas del movimiento para la autonomía indígena.

La combinación de la enseñanza del documental como una forma comunicativa de compromiso social junto a la idea de la tecnología como algo transparente formó un género específico —el video indígena- que muestra ciertas debilidades frente a asuntos comunitarios en Tama, como veremos más a delante. Dichas carencias tienen que ver con una creencia sobre la capacidad del medio de "mostrar cultura", de hacer el trabajo del activista social sin realizar lo necesario para encajar el proyecto dentro de la dinámica social y estructuras de poder de una comunidad indígena. En fin, el poder del documental de comunicar y convencer se vio comprometido al suscribirse al modismo del espejo electrónico, en vez de mostrar que el videasta indígena - y por extensión el video que produce- ocupa una posición particular que le da su poder. ${ }^{6}$ Esta contradicción tal vez está en la base de la "profunda confusión" que identificó el maestro Cruz. Pasaremos enseguida a la discusión del proyecto de Radio y Video Tamix.

\section{Radio y Video Tamix: Ubicación de una organización de medios en la comunidad}

Llegué a Tama al iniciar mi investigación de campo en la noche del primer y principal tequio o labor comunal que se llevaba a cabo en los campos recientemente chapeados al centro del conflicto agrario con un pueblo vecino, Santa María Tlahuitoltepec - Tlahui en corto-. Dado el "estado de guerra" entre los dos pueblos, dudaba si había sido la mejor decisión llegar a Tama en un autobús administrado por el pueblo de Tlahui. Le pedí a un señor que viajaba a mi lado, que me avisara cuando llegáramos a Tama. Era de noche, pero con su ayuda pude bajarme en la curva correcta. Cuando me vieron, un topil —el sirviente civil en el rango más bajo del sistema de cargos comunales - quien convocaba a los comuneros en su idioma aymuk al tequio que tendría lugar, hizo una pausa y pasó el micrófono a la telefonista para que le llamara por éste medio al maestro Clemente Nuñez, un miembro fundador de Radio y Video Tamix, para que fuera a su casa a recibirme. Conocía Clemente por primera vez en 1993 en una conferencia de antropología en la Ciudad de México y participé junto con él en numerosas presentaciones de video indígena en Oaxaca y también en Nueva York, donde él presentó el video de su organización titulado Moojk/ Maíz en el Festival de Cine y Video Indígena de 1995 — uno de los años en los que fui la coordinadora de la selección de los programas de América Latina-. En esta ocasión, sin embargo, me encontraba por primera vez en su comunidad.

Me desperté el día siguiente a las seis de la mañana con el sonido del cuerno que llamaba todos al tequio mezclados con los sonidos cotidianos de la mañana: el cantar de los gallos y la música variada de diferentes programas de radio. Mientras dejábamos el centro de Tama, pasando por caminos angostos entre pequeñas casas y patios, el humo de las fogatas en el sitio del tequio estaba saliendo del valle. Gente de todas las edades - aunque en su mayoría adultos y ancianos- que cargaban herramientas rústicas de cultivo, llegaron a la veredita en que me encontraba hasta que formamos una corriente que fluía bajando en fila hacia el río. Los campos ya se encontraban en gran y organizada actividad. Filas de gente arando rítmicamente los 
campos recién chapeados, que parecían extenderse hasta donde llegaba la vista; un buey con su arado hacía hábilmente surcos por donde ya había pasado la gente. La mezcla de olores, sonidos y texturas colmaban el ambiente decididamente: pedazos de tierra fresca, desechos crujientes y humo en fogatas masivas, bueyes cuyo sudor salía como vapor de su cuerpo en el aire fresco de la mañana, los látigos y las canciones de los aradores, el agua borboteando alrededor de las rocas en el cauce del río. Fue una introducción espectacular y sensual a Tama y al significado de la comunidad del tequio. Las imágenes del tequio grabadas en video emergen como propuestas visuales clave de la vida colectiva empleadas por Radio y Video Tamix para ubicarse a sí mismos como una organización comunitaria.

\section{De la Casa del Pueblo a la Radio y Video Tamix}

El programa de video del INI desempeñó un papel crucial en el desarrollo de Radio y Video Tamix, la organización de comunicadores de Tama. Cuando los miembros de Tamix participaron en el programa del INI, la organización ya se había transformado a partir de un grupo libre de maestros de escuela que trataban de entretenerse a sí mismos y a su comunidad, donde se organizaban concursos y bailes en un centro cultural llamado la "Casa del Pueblo" con fondos del estado y un modesto presupuesto anual de 10,000 pesos en 1989. La Casa del Pueblo funcionaba también como un centro de producción radiofónico para la estación regional indígena del INI que se encontraba en el pueblo zapoteco de Guelatao de Juárez. En 1990 el grupo contactó a un paisano emigrado a los Estados Unidos para que les trajera una cámara de video, la cual utilizaron para grabar sus sesiones de producción radiofónica, visitas oficiales, fiestas patronales y las principales actividades de la municipalidad como el "cambio de autoridades", celebrado el primero de enero de cada año. En 1992, dos miembros de la Casa del Pueblo participaron en el segundo taller nacional de video del INI, y poco después la organización anunció su nuevo proyecto: la "Radio y Video Tamix" — seguidamente se abreviará Tamix.

El taller de producción de video del INI no sólo transfirió equipo de producción de video y conocimientos básicos para su uso, sino también el discurso institucional acerca del papel de la cultura en el desarrollo de las comunidades indígenas y la idea sobre cómo la representación de sí mismos por medio del video podía reforzar la identidad de la comunidad. $\mathrm{Si}$, como lo señaló Clemente, al iniciar la Casa del Pueblo no se hablaba de "rescate cultural", en 1992, cuando Tamix imprimió su primer folleto promocional, ya se encontraba como un objetivo "primordial" el "rescatar, preservar y promover la cultura mixe por medio de grabaciones y del uso de equipo de video, porque sabemos que la comunicación es un medio para reforzar nuestra identidad" (Tamix, 1992). Como hemos visto en la primera sección, el trabajo social que describe el folleto de Tamix se alcanza con la tecnología misma: viéndose en el espejo electrónico hace que nazca la conciencia de identidad como un aspecto de lucha social. Aunque, en realidad el proceso no es tan directo ni tan sencillo.

La consolidación de Tamix se completó con el "descubrimiento" de un equipo transmisor de televisión. Los conocimientos recién adquiridos en el taller nacional de video, así como el incremento significativo del equipo donado por el INI, les permitió apropiarse de un transmisor abandonado y jamás utilizado. El transmisor había sido originalmente instalado en Tama como parte de una red de retransmisión rural de IMEVISION. Ésta empezó como un proyecto del Estado que fue privatizado en $1980 \mathrm{y}$ comprado por TV Azteca, una de las redes televisivas comerciales más grandes de México. El transmisor de 10 watts manda la señal de Tamix a un área limitada 
—máximo 5 kilómetros—, pero debido a que su frecuencia se encuentra prefijada en el canal 12, su señal interrumpe la programación de TV Azteca, no sólo una de las señales más fuertes que llegan a Tama, sino también uno de los recursos más populares para acceder a telenovelas y noticias.

\section{"TV Tamix Presenta": Estableciendo las bases}

TV Tamix inicia sus transmisiones televisivas con una serie de agradecimientos a las autoridades simbólicas y reales más importantes, empezando por la montaña sagrada, la nación mexicana a la que pertenecen y la comunidad. Esta serie de pedidos representan un esfuerzo por insertar el proyecto de televisión dentro de la comunidad. Cuando inicia el himno nacional mexicano, tomas panorámicas y el uso del zoom introducen al sagrado Zempoatepetl, uno de los picos más altos en Oaxaca y el lugar en el cual según la leyenda nació de un huevo la deidad mixe, el Rey Kong Hoy. Los ocho versos del himno se escuchan mientras se ven imágenes de la comunidad en algunos momentos muy concurridos del tequio y en ceremonias que dan la bienvenida al nuevo consejo de gobierno. Una enorme piedra es soltada de un lado de la montaña mientras que miembros de la comunidad abren a mano un nuevo camino. Una estructura de concreto de dos pisos del mercado está casi lista mientras los residentes acarrean pesados baldes de concreto por las delgadas rampas que van al techo. Una multitud da la bienvenida al recién elegido consejo con velas y flores y desfila bajo los arcos del palacio municipal y la bandera mexicana. Cuando se escucha el himno mixe que prosigue, los productores de la televisión Tamix se presentan mientras trasmiten su señal desde el sitio original en la escuela secundaria, y muestran su estudio, la forma en que graban los programas de radio y cómo editan video con el equipo donado. Por lo tanto, la autonomía mixe, evocada por el himno mixe, está visualmente ligada al uso de equipo de alta tecnología, y en el proceso se propone también una identidad local que abraza la tecnología moderna.

El folleto de la organización ubica firmemente a TV Tamix dentro de la comunidad, pero se le subordina al reconocer que su "máxima autoridad es la asamblea general de los comuneros o de los propietarios" (Tamix, 1992). En especial, evocan al tequio para ejemplificar su posición como un proyecto de comunidad y adoptan el término "espacio sagrado" para señalar la importancia simbólica — significado simbólico- de la estación, para indicar que el hacer video y televisión es tan sagrado como el tequio. Una connotación que le agrada a algunos miembros del programa de TMA, ya que ejemplifica una indigenización positiva de la tecnología presentada por el INI. Además, hacen un listado con los nombres de los miembros y se describen como "personas cuya lengua materna es el mixe y que prestan su servicio voluntariamente de una manera considerada como tequio" (Tamix, 1992).

La presentación de la estación continúa después del himno mixe con varias secuencias acompañadas por una narración que, como su folleto, está en castellano e imita promocionales de estaciones de radio y televisión comerciales: "Porque sabemos que la comunicación es una herramienta fundamental para el desarrollo y fortalecimiento de nuestra cultura e identidad. ¿Quiénes somos? ¡Radio y Video Tamix de Tamazulapam Mixe transmitiendo con 10 watts de potencia! La nueva forma de ver y escuchar, los sábados a las cuatro de la tarde por el canal 12 en sus aparatos receptores". La parte final de la presentación es una canción local dedicada a las mujeres de Tama y a sus trajes. Mientras que existe conciencia entre los residentes de Tama del papel que tiene el traje tradicional para mostrar autenticidad a las audiencias foráneas, las tomas de mujeres que trabajan en el campo, preparando comida y ofrendas religiosas, conectan claramente a la estación 
con una de las características culturales únicas y más visuales de Tama. Por medio de esta secuencia, la televisión Tamix confiere respeto no sólo a las mujeres y a los ancianos - grupos sociales ausentes en la organización — sino también al panteón de deidades a las que las mujeres suplican por medio de prácticas diarias de ofrendas y sacrificios. Cada sección de la introducción está separada con una toma fija de "barras de colores" culturales de Tamix, utilizando el rebozo de las mujeres, como un traslape simbólico divertido.

Luego de esta serie de agradecimientos a la nación mexicana, a la comunidad y a las deidades, la transmisión de la televisión Tamix continua con una variedad de programas que consisten en su mayoría en grabaciones originales poco editadas de los asuntos del pueblo, como graduaciones escolares y visitas de los oficiales del gobierno, aunque ocasionalmente lanzan al aire algún documental del INI. Entre 1992 y 1995 , Tamix, movió la antena del patio de la escuela y la erigió nuevamente en el techo del palacio municipal de Tama desde donde se ha vuelto a transmitir. Durante este tiempo, varios jóvenes del poblado —en especial el hermano menor de Clemente, Gilberto, y su primo Esteban, que habían llegado recientemente de Veracruz - se entrenaron en el Centro de Video Indígena del INI de la ciudad de Oaxaca y se hicieron miembros activos de Tamix. Hacia finales de 1998, Tamix estaba en el aire con un nuevo programa cuyo tema versaba sobre los niños: "Hoy en la comunidad". Programa producido, en parte, con fondos de una institución nacional para infantes. Creado por iniciativa personal de Esteban, "Hoy en la comunidad", "es un espacio abierto para todos los miembros de la comunidad interesados en hablar y reflexionar sobre eventos que ocurren en el desarrollo de nuestro pueblo Ayuuk" (Tamix, 2000).

\section{"Hoy en la Comunidad": Ampliación de las bases}

Algunas tomas del tequio son aún empleadas en la secuencia de presentación de "Hoy en la Comunidad", pero ahora música rock acompaña las imágenes, en vez de himnos o canciones tradicionales, y el estilo de los encuadres es menos tentativo, más intencionado. En lugar de enfocarse en imágenes de la comunidad, la presentación del programa es un montaje de momentos vividos en el estudio de la televisión Tamix. Diferencias notables en estilo y tono de la presentación anterior reflejan desacuerdos más profundos entre la "generación" de los miembros fundadores y los más jóvenes, acerca de lo que constituye una programación apropiada y sobre el papel que deben de jugar los medios de comunicación en la comunidad. Sus programas tratan, de hecho, de lo que sucede en el pueblo. Un día, el Estado patrocinó una campaña sobre higiene dental, lo que impulsó a Gilberto y Esteban a alistar los niños de la primaria para explorar sus prácticas de higiene; y en la noche, en un programa de información con representantes de la organización Alcohólicos Anónimos, editaron un corto llamado "Mareados con la Chela". Este corto empieza con la actuación de una borrachera de cerveza y sigue con tomas - reales y actuadas - de miembros de la comunidad que se encuentran inconscientes, tirados en el suelo después de la fiesta patronal. Una música melancólica de violín clásico dramatiza la tragedia del alcoholismo en Tama, lo que se acepta socialmente como un problema en la comunidad.

Clemente no estaba de acuerdo con lo que la generación más joven de videastas considera como material "indígena" y "cultural." En su opinión, los videos indígenas en castellano no son verdaderamente indígenas y también se opone a los programas de Esteban, argumentando que éstos no enfatizan los aspectos estrictamente "culturales" que él considera 
importantes o apropiados. Tanto Gilberto como Esteban, sin embargo, piensan que su programación debe ser actual, acerca de lo que está pasando en su poblado, y "Hoy en la comunidad" pone de manifiesto sus esfuerzos por sustraer la programación de Tamix del control de Clemente, para hacerla más "neutral", como ellos entienden que deberían ser los medios de comunicación. Para la generación más joven, se está viviendo un periodo de cambios fuertes y sostienen que la definición de Clemente sobre la cultura indígena es muy rígida y exclusiva. En la opinión de estos jóvenes, su mejor espectáculo fue una tarde de música y entrevistas con el grupo de rock "Ruina Jade" del Distrito Federal. Aún bajo el "riesgo de serinauténtico," para usar un término que Levi y Dean utilizan en su reciente libro sobre los derechos indígenas (2003), Gilberto y Esteban enfatizan una versión más constructiva o menos esencial de la identidad indígena ante la versión más conservadora de Clemente que, no por casualidad, refleja el uso de la cultura como folclor que maneja el INI. Los desacuerdos sobre el contenido generan nuevos debates acerca de la identidad cultural en la comunidad y demuestran la pluralidad de posiciones que se constituyen en el video indígena.

\section{Crisis en la organización}

Como organización, Tamix resuelve estos desacuerdos al permitir que cada miembro desarrolle su propio proyecto. Sin embargo, hay conflictos más profundos entre la organización y la comunidad que han sido más difíciles de resolver. En 1996, Radio y Video Tamix ganó una beca del Fondo Estatal para la Cultura y las Artes (FOESCA) de Oaxaca de unos 80000 pesos y una beca de 12000 dólares de las Fundaciones MacArthur y Rockefeller, lo que significó un incremento extraordinario de su presupuesto anterior. El reconocimiento internacional a la organización y, aún más importante, el colchón de seguridad económica desconocido hasta ahora, fueron rápidamente ensombrecidos por el incremento de una actitud hostil hacia ellos por parte de miembros de su comunidad. A pesar de los esfuerzos por arraigar el proyecto de representación audiovisual de la comunidad por medio de la evocación visual de usos colectivos, Tamix fue acusada por miembros de la comunidad de corrupción y evasión fiscal. Al parecer, el espejo electrónico y la fe del grupo en la supuesta capacidad del video de representar con transparencia no fueron suficiente para convencer al pueblo de su proyecto. Estas acusaciones culminaron con la expulsión de los comunicadores y su equipo del palacio municipal, un acontecimiento que efectivamente dividió a la Casa del Pueblo y a Radio y Video Tamix en distintas organizaciones.

El grupo perdió a varios de sus miembros durante la separación y las transmisiones de televisión casi se detuvieron durante 1997, pues Tamix no clausuró su programación por completo. De hecho, el conflicto generó oportunidades inesperadas para que miembros jóvenes asumieran papeles más activos. Menos vulnerables a la crítica de la comunidad por su juventud — tenían cerca de 18 años en ese periodo—- Gilberto y Esteban, efectivamente mantuvieron a la organización con vida. A diferencia de los miembros fundadores de la Casa del Pueblo que eran maestros de profesión, ellos no tenían otros trabajos o familias que mantener. Además, Gilberto y Esteban sentían que habían "crecido" en Tamix y que no podían dejar este proyecto "así nomás". Tamix reestableció sus operaciones en un nuevo local en 1997 y gastó gran parte de las dos becas para renovar el edificio y equipar el nuevo estudio de televisión. Al llegar a Tama por el camino pavimentado desde la ciudad de Oaxaca, resalta a la vista el que es el letrero más visible del pueblo. Anunciándose sobre los letreros coloridos de la publicidad de cerveza en unas paredes alrededor del pueblo, TV T-A-M-I-X también se encuentra pintado sobre la fachada del estudio, reclamando físicamente una posición central en la comunidad, imposible de ignorar. 
Cambios en la programación televisiva y una nueva producción de video se hicieron manifiestos en la actividad del grupo en 1997 y gran parte de 1998, lo que reflejó tanto sus obligaciones hacia las instituciones donantes como una relación más cuidadosa con la comunidad. Sin embargo, hacia finales de 1998, cuando el conflicto agrario entre Tama y Tlahui se acentuó, algunos miembros de Tamix pudieron trabajar en cooperación con el consejo municipal por primera vez en casi dos años. Se le pidió al grupo grabar los encuentros de negociación y varios días de tequio, durante los cuales se consolidó la frontera municipal de Tama con mojoneras grandes, mientras áreas extensas de tierra en disputa fueron chapeadas para el cultivo. El primer tequio al que asistí en Tama era el segundo de una serie de tequios que la comunidad había dedicado al reclamo de facto de esta tierra en conflicto. A pesar de esta legitimación de TV Tamix por parte del consejo municipal, varios comuneros pidieron a Gilberto y Esteban que dejaran de grabar y que agarraran una coa, lo que en otras palabras significaba que hicieran un trabajo "verdadero". El tequio no es sólo uno de los símbolos más importantes de la vida de la comunidad colectiva — como enfatiza también TV Tamix en su programación — sino es también obligatorio en Tama y por ello un asunto serio. Desde 1998, el tequio es, además, reconocido legalmente por la constitución del estado de Oaxaca. Un comunero que no asiste al tequio es multado o se le encierra un día en la cárcel local. El filmar, ante los ojos de muchos comuneros, no es un trabajo comunal legítimo y, por lo tanto, no constituye una liberación de tal compromiso. Comparado directamente con el trabajo intensivo de campo, cargar una cámara en el hombro, o peor, en la palma de la mano, no es considerado como trabajo "verdadero" en el sentido físico. Tal trabajo "verdadero" del cultivo del maíz sin duda está profundamente conectado con el sentido de ser mixe. A pesar de que Tamix utiliza imágenes del tequio en sus programas de televisión para ubicarse como grupo comunitario ante la comunidad misma, el acto de grabar el tequio sirvió como una forma de rechazar al grupo y negar la validez de su trabajo.

\section{Fin de la crisis}

La discusión entre los miembros del grupo frente a estos conflictos se centraba en dos planteamientos: por un lado se quería normalizar el trabajo de Radio y Video Tamix como cargo comunal y, por el otro, se planteaba la problemática de "ver la cultura". La posición intermedia de Radio y Video Tamix en la comunidad le proporciona cierta libertad y control de su producción y programación pero también serias desventajas. Clemente enfatizaba a menudo que el video y la televisión de la comunidad deberían ser incorporados al sistema de trabajos de la comunidad o como un servicio requerido por la comunidad, del mismo modo que el participar en la banda filarmónica municipal. De esta manera, sus actividades serían transparentes para toda la comunidad y Tamix potencialmente tendría recursos fiscales y humanos más seguros. Además, si el trabajo de producir medios de comunicación en la comunidad fuera regulado y percibido como un cargo, desde el punto de vista de los comunicólogos locales, el no ser compensados económicamente por su trabajo se justificaría mejor ya que todos los trabajos comunales son voluntarios. En la actualidad, los jóvenes que se han capacitado en Tamix tienden a abandonar la organización porque sienten que ahí no tienen futuro económico. Por su parte, los veteranos han expresado su frustración cuando los jóvenes capacitados por ellos se han ido en busca de mejores oportunidades económicas. La idea de normalizar dicho trabajo no tuvo eco, como tampoco la tuvo la preocupación que ventiló una mujer de la comunidad acerca de la continuidad de Tamix. Como ella me explicó, la comunidad está 
acostumbrada a que los cargos sean rotados anualmente. Tamix no tiene ese perfil pero ocupa una posición de poder en la comunidad, el poder de representar la comunidad dentro y fuera del pueblo. El hecho de que las mismas personas, e incluso la misma familia, han sido asociadas con Tamix desde el inicio ha fomentado la sospecha de que la organización de comunicadores es un negocio para obtener ganancias personales, no un servicio comunitario.

Los miembros de Tamix, tanto los recién llegados como los fundadores, centran sus esfuerzos en la problemática de representar la cultura en video. Según éstos, Tamix trabaja con medios audiovisuales "para que la gente se vea". El mostrar videos mixe en su propia comunidad es motivado por la convicción de que el verse a sí mismos sirve para estimular el pensamiento crítico y generar procesos reflexivos. De acuerdo con Gilberto: "Cuando hablas no te escuchas a ti mismo hasta que alguien te dice lo que dijiste". Aquí el "espejo electrónico" que introdujo el INI se transformó en una herramienta para promover un cambio social basado en la autorreflexión. Sin duda, el video —y más la televisión local— tiene éxito como película casera - a los miembros de la comunidad les gusta verse en televisión- pero el proceso de producción permanece opaco, y por lo tanto, genera sospechas en la mayoría de los miembros de la comunidad. En palabras de otro veterano de Tamix, Rodrigo, la gente no valora lo que hacen porque "no ven la cultura" como verían la construcción de una casa. La gente sabe lo que cuesta en trabajo y dinero la construcción de una casa, el hacerla "bien" y "bonita". Sin embargo, explica, no pueden ver hacia dónde va el dinero para una producción de video. Gilberto compara el video con el pan: "el video no es como hacer pan donde el producto es visible y todos lo compran". En otras palabras, el proyecto de Tamix hace la cultura visible en video, pero la producción misma del video permanece invisible.
Como tantos otros activistas indígenas, los productores de Radio y Video Tamix tratan de fomentar cambios en su comunidad. Clemente con frecuencia decía que él quería que su gente "despertara" para poder cuestionarse y criticar, para darse cuenta de lo que tienen. Su toque personal se basa en el humor y la espontaneidad que se manifiesta, por ejemplo, cuando coloca los cuernos de venado encima de la videocámara o realiza transmisiones de televisión en broma avisando la llegada de estrellas de rock parisinas al centro de Tama. No obstante, cuando él junto con otros miembros de Tamix abrazaron los programas del gobierno, su proyecto inicial de divertir y despertar a la gente tomó otro rumbo y se transformó en un proyecto de rescate cultural y de reforzamiento de identidad.

Si volvemos por un momento a la etapa de los talleres nacionales de producción de video del programa de TMA, recordaremos que los maestros se apoyaban en la idea del espejo electrónico para presentar y enseñar el video como una tecnología transparente. A la vez propiciaban un activismo social con base en la representación cultural y la autorreflexión con la misma lógica que luego utilizaban los miembros de Tamix cuando explicaron que el video era un espacio que generaba reflexión. Hay ejemplos muy claros sobre cómo el verse en video motiva directamente un proceso tendiente a retomar ritos o costumbres ya perdidos (Aufderheide, 1995). Sin embargo, el problema que articula Rodrigo, de que la gente no "ve la cultura" tiene que ver con el poner una sobrecarga de responsabilidad en el medio mismo — una fe exagerada en el "espejo electrónico- en vez de centrar su atención en procesos sociales mucho más complejos, que toman mucho más tiempo que el acto de grabar y proyectar una imagen en video. Tanto los maestros del programa de TMA como los miembros de Tamix buscan maneras de insertar o traducir culturalmente el "video indígena" al "mundo indígena"; los primeros, con el uso de la técnica del "espejo electrónico"; y los 
segundos, al presentarse bajo los poderes del mundo mixe y al enfatizar el colectivismo y la utilidad de ciertos toques visuales locales, aunque ambos esfuerzos enfrentan serios obstáculos sociales. Lo que quiero señalar con esta reflexión es que al concebir el video indígena como práctica social, más que como una mera tecnología, nos damos cuenta que no es algo directo, transparente o dado. El video indígena se construye como la identidad cultural indígena, a través de prácticas y relaciones sociales complejas y propone una posición particular, parcial y siempre política. Los individuos, instituciones e intereses involucrados en la producción del video indígena demuestran cómo, hasta las identidades basadas en una ubicación geográfica, se producen pluralmente por medio de arenas múltiples y sobrepuestas que incluyen comunidades locales, centros regionales, burocracias nacionales del gobierno y redes transnacionales, como los festivales de cine y video indígena, ámbito desde el cual empecé a conocer y apoyar a los realizadores indígenas de México. Un resultado de este reconocimiento es que la hibridad no alcanza a describir de manera adecuada al video indígena como proceso y forma social: éste se encuentra en un espacio analítico mucho más allá, en lo múltiple y plural. En el proceso, este análisis del video indígena puede potencialmente conducir el discurso de la identidad indígena más allá de la interacción entre participación política y autenticidad que Levi y Dean, (2003) usan para enmarcar su discusión de los derechos indígenas — y más allá de la hibridad — lo que libera la identidad indígena de la garra de la autenticidad. La autorrepresentación indígena es algo central para las luchas más amplias de autodeterminación y autonomía, como los desafortunados pero aún valiosos Acuerdos de San Andrés claramente señalan. Esta breve y parcial historia del video indígena y de Radio y Video Tamix, demuestra que el proceso de articular identidades indígenas "en casa" y dentro de los circuitos discursivos fuera de la comunidad, es algo complejo y que debemos mantener esa complejidad y pluralidad en nuestra comprensión de tales procesos sociales tan dinámicos.

\section{Notas}

${ }^{1}$ La autonomía indígena es un tema discutido y vivido en formas muy variadas. En general me refiero a un proceso político y organizado que tiene ramas articuladas y desarticuladas con un movimiento social que se constituye en ámbitos locales, regionales, nacionales y globales, dentro del cual los principales protagonistas son activistas indígenas que ejercen su derecho a la autodeterminación. La autodeterminación también es un concepto muy discutido y básicamente concierne los derechos de definir su propia cultura, gobierno y el manejo de los recursos naturales (véase Stavenhagen, 1990, 1992; y Van Cott, 1994, 2001).

${ }^{2}$ En mayo de 2003, el presidente mexicano, Vicente Fox Quesada anunció el fin del INI después de 54 años de existencia; o más precisamente la transformación legal de esta institución en Comisión Nacional para el Desarrollo de los Pueblos Indígenas (CONADEPI). En el presente artículo me refiero al llamado "video indígena" como un proyecto del INI dentro de un marco nacional e histórico específico y no a otros proyectos comparables que han existido en otras partes de América Latina y el mundo, como son Video Nas Aldes ("Video en las Aldeas") (Aufderheide, 1995) y el Proyecto de Video Kayapo (Turner, 1991) en Brasil, por mencionar dos de los casos más conocidos.

${ }^{3}$ Cabe señalar que el INI llevaba más de quince años desarrollando un sistema nacional de radios indígenas cuando empezó el proyecto de TMA. De hecho, varios de los videastas indígenas que colaboraron en mi investigación llegaron al video después de haber trabajado en la radio. Sin embargo, el proyecto de video surgió de diferentes iniciativas y con metas menos definidas. La diferencia que más llama la atención en comparación con la radio, es la falta de una red nacional de video-difusión. El antecedente más relevante y directo del proyecto de video indígena del INI no son las radios, sino un proyecto de cine- 8 de corta duración que involucró a un grupo de tejedoras ikood de San Mateo del Mar, Oaxaca, en 1985 y del cual salió el documental Tejiendo Mary Viento (INI, 1986).

${ }^{4}$ Aunque el proyecto de TMA surgió de manera autónoma o independiente, es decir, las personas involucradas en su desarrollo pensaron que estaban creando algo completamente nuevo, existen similitudes importantes con otros proyectos 
ya encaminados en la década de 1980 como, por ejemplo, el Proyecto de Video Kayapo en la Amazonia de Brasil. De acuerdo con un argumento central de Terrence Turner (1991) sobre esta experiencia, podemos afirmar que el proyecto de TMA demuestra igualmente una estrecha conexión entre el video o la representación visual y la objetivización de la cultura.

${ }^{5}$ Todos los actores en esta historia tienen vidas relativamente públicas en términos de su participación en el proyecto de video indígena, algunos de ellos más que otros. En el presente trabajo he decidido usar seudónimos para los actores que tienen una vida menos pública.

${ }^{6}$ Es una dinámica difícil, como afirma también Turner (1991) en su relato de los problemas con el video y el poder local entre los kayapo.

\section{Bibliografía}

Aufderheide, Patricia, 1995, "The Video in the Villages Project: Videomaking with and by Brazilian Indians", Visual Anthropology Review, Vol. 11, Núm. 2, pp. 83-93.

Becerril, Alberto (realizador), 1986, Tejiendo Mary Viento. La Vida de una Familia Ikood, documental, formato Super-8, duración de 23 minutos, INI, Oaxaca.

Bhaba, Homi, 1994, The Location of Culture, Routledge, New York.

Centro de Video Indígena del InI, 1996, Oaxaca, México.

Cremoux, Daniela, 1997, Video Indígena. Dos Casos en la Sierra Mixe, Tesis de Licenciatura, Universidad Intercontinental, México.

Cruz, Carlos, 2000, Entrevista, México.

García, Juan José, 2000, Entrevista, Ciudad de Oaxaca.

García Canclini, Néstor, 1989, Culturas Híbridas: Estrategias para entrary salir de la modernidad, Consejo Nacional para la Cultura y las Artes y Editorial Grijalbo, México.

Ginsburg, Faye, 1993, "Aboriginal Media and the Australian Imaginary”, Public Culture, Vol. 5, Núm. 3, pp. 557-578.

Hall, Stuart, 1996, "Introduction: Who Needs Identity?", en S. Hall y P. du Gay (eds.), Questions of Cultural Identity, Sage Publications, Londres, pp. 1-17.

Julián Caballero, Emigdio, 1994, "La T.V. No Es Realidad", en Muestra Interamericana de Videoastas Indígenas, pp. 8-9, INI, México.

Kearney, Michael y Stefano Varese, 1995, “Latin America's Indigenous Peoples: Changing Identities and Forms of
Resistance", en S. Halebsky y R. L. Harris (eds.), Capital, Power and Inequality in Latin America, Westview Press, Boulder, pp. 207-231.

Kuroda, Etzuko, 1984, Under Mt. Zempoaltépetl: Highland Mixe Society and Ritual, Museo Nacional de Etnología, Osaka, Japón.

Levi, Jerome M. y Bartholomew Dean, 2003, "Introduction”, en Bartholomew Dean y Jerome M. Levi (eds.), At the Risk of Being Heard: Identity, Indigenous Rights and Postcolonial States, University of Michigan Press, Ann Arbor, pp. 1-44.

Lupone, Luis y Teófila Palafox, 1987, Tejiendo Mary Viento. La Vida de una Familia Ikood, documental, formato Super-8, duración de 23 minutos, INI, Oaxaca.

Radio y Video Tamix, 1992, Folleto de la organización, Tamazulapam Espíritu Santo, Oaxaca.

Radio y Video Tamix, 2000, Folleto de la organización, Tamazulapam Espíritu Santo, Oaxaca.

Redfield, Robert, 1968, The Folk Culture of Yucatan, University of Chicago Press, Chicago.

Stavenhagen, Rodolfo, 1990, "Derecho Consuetudinario Indígena en America Latina", en R. Stavenhagen y D. Iturralde (eds.), Entre la ley y la costumbre, Instituto Indigenista Interamericano, México, pp. 27-46.

—, 1992, "Challenging the Nation-State in Latin America", Journal of International Affairs, Vol. 34, Núm. 2, pp. 421-440.

Turner, Terrence, 1991, “The Social Dynamics of Video Media in an Indigenous Society: The Cultural Meaning and Personal Politics of Video-making in Kayapo Communities," en Visual Anthropology Review, Vol. 7, Núm. 2, pp. 68-72.

Van Cott, Donna Lee, 1994, "Indigenous Peoples and Democracy: Issues for Policymakers", en D. L. Van Cott (ed.), Indigenous Peoples and Democracy in Latin America, St. Martin's Press en asociación con The Inter-American Dialogue, New York. pp. 1-27.

Van Cott, Donna Lee, 2001, "Explaining Ethnic Autonomy Regimes in Latin America", Studies in Comparative International Development, Vol. 35, Núm. 4, pp. 30-58.

Worth, Sol y John Adair, 1997, Through Navajo Eyes: An Exploration in Film Communication and Anthropology, University of New Mexico Press, Albuquerque. 